\title{
Preliminary report on surgical mask induced deoxygenation during major surgery*
}

\author{
A. Beder; *Ü. Büyükkoçak; **H. Sabuncuoğlu; ***Z.A. Keskil and ****S. Keskil
}

Başkent University. Faculty of Health Sciences. Department of Nursing and Health Services. Ankara, Turkey; *Kirikkale University. Faculty of Medicine. Departments of Anaesthesiology and Pharmacology***. Kirikkale. Turkey. **Ufuk University, Faculty of Medicine, Department of Neurosurgery. Ankara, Turkey. ****Bayindir Medical Center, Department of Neurosurgery. Ankara. Turkey.

\section{Summary}

Objectives. This study was undertaken to evaluate whether the surgeons' oxygen saturation of hemoglobin was affected by the surgical mask or not during major operations.

Methods. Repeated measures, longitudinal and prospective observational study was performed on 53 surgeons using a pulse oximeter pre and postoperatively.

Results. Our study revealed a decrease in the oxygen saturation of arterial pulsations $\left(\mathrm{SpO}_{2}\right)$ and a slight increase in pulse rates compared to preoperative values in all surgeon groups. The decrease was more prominent in the surgeons aged over 35.

Conclusions. Considering our findings, pulse rates of the surgeon's increase and $\mathrm{SpO}_{2}$ decrease after the first hour. This early change in $\mathrm{SpO}_{2}$ may be either due to the facial mask or the operational stress. Since a very small decrease in saturation at this level, reflects a large decrease in $\mathrm{PaO}^{2}$, our findings may have a clinical value for the health workers and the surgeons.

KEY WORDS: Surgery. Surgical Mask. Oxygenation. Operation. Oxygen saturation. Facemask.

Comunicación preliminar sobre desoxigenación inducida por la mascarilla quirúrgica durante la cirugía de larga duración

\section{Resumen}

Objetivos. Este estudio se realizó para determinar si la saturación de oxígeno del cirujano se afectaba por el uso de la mascarilla, durante intervenciones de larga duración.

Métodos. Se hizo un estudio longitudinal y prospectivo en 53 cirujanos con medidas de la hemoglogina realizadas con un oxímetro para medir la saturación del pulso arterial. Se hicieron estudios antes y

Recibido: 13-03-07. Aceptado: 6-06-07 después de la operación.

Resultados. Nuestro estudio puso de manifiesto una disminución de la saturación de oxígeno de las pulsaciones arteriales $\left(\mathrm{SpO}_{2}\right)$ y un ligero aumento de las pulsaciones en comparación con el estado preoperatorio en todos los grupos de cirujanos. La disminución era mayor en el grupo de edad superior a los 35 años.

Conclusiones. Según nuestros hallazgos, el ritmo del pulso aumenta y la concentración de $\mathrm{SpO}_{2}$ disminuye después de la primera hora de la operación. Este cambio temprano de $\mathrm{SpO}_{2}$ puede deberse a la mascarilla o al estrés de la intervención. Puesto que un ligero descenso en la saturación a este nivel refleja una mayor disminución de la $\mathrm{PaO}_{2}$, nuestros datos pueden tener un valor clínico para la salud del personal sanitario y para los cirujanos.

PALABRAS CLAVE: Cirugía. Oxigenación. Operación. Saturación de oxígeno. Mascarilla.

\section{Introduction}

Soon after the introduction of surgical masks by Mikulicz $z^{5}$ in 1897 , their usage in the operating theatre became a standard practice. Although there appears to be a shift from a patient-protective standpoint to a healthcare worker-protective standpoint in recent years, it is generally accepted that operating theatre staff has to wear surgical masks and change it partway through long procedures (4 hr or more) $)^{6}$.

Surgeons in the operating room frequently experience physical discomfort, fatigue, and possibly even deterioration of surgical judgment and performance. Although considerable information exists about the effects of ambient environment on both mental and physical performance, the final "personal" environment for the surgeon beneath the surgical mask is often very inadequately conditioned

*The work was done in the surgical theaters of Kirikkale University, Faculty of Medicine and Fatih University, Faculty of Medicine 
despite the universal air-conditioning standard of operating theaters. Thus they either wear masks improperly or refrain from using them altogether. As it is known that heat and moisture trapping occur beneath surgical masks, it seems reasonable that some of the exhaled $\mathrm{CO}_{2}$ may also be trapped beneath them, inducing a decrease in blood oxygenation.

"Normal blood $\mathrm{O}_{2}$ saturation" is usually defined as a fractional saturation of 90 to $97.5 \%$, which corresponds to an arterial oxygen partial pressure of 13.3 to $13.7 \mathrm{kPa}$, if there are no other hemoglobin species, apart from oxyand reduced hemoglobin. A pulse oximeter can detect the oxygen saturation of hemoglobin quickly, in an accurate, and reliable way. Pulse oximeters combine oximetry and plethysmography to measure arterial oxygen saturation, noninvasively. According to Lambert Beer Law, oxygenated and reduced hemoglobin absorb red and infrared light differently. Oxyhemoglobin absorbs more infrared light, while reduced hemoglobin absorbs more red light. The ratio of absorptions at the red and infrared wavelengths is analyzed by oximetry to give the oxygen saturation of arterial pulsations ${ }^{4}$.

The primary focus of this study was to measure the surgeons' oxygenation status while they were engaged in their daily routine activities of major operations.

\section{Materials and methods}

53 surgeons from both sexes, employed at university hospitals, 24 to 54 years old, non-smokers and without any chronic lung disease were studied by pulse oximetry before and after the course of an operation. They were hemodynamically stable, breathing room air and standing throughout the operations.

The groups were formed according to the duration of the operations:

I. Duration of the operations was up to 60 minutes, Ia: group wearing mask $(\mathrm{n}=5)$

Ib: group of surgeons who did not wear mask during primary care operations with duration of less than 30 minutes $(n=9)$

II. Duration of the operations was in between $60-120$ minutes $(n=25)$.

III. Duration of the operations was in between 120-180 minutes $(n=23)$.

IV. Duration of the operations was in between 180-240 minutes $(n=20)$.

In order to estimate whether age has any effect on oxygen saturation of hemoglobin and pulse rate, surgeons were also divided into two age groups according to the median age: Surgeons under the age of $35(\mathbf{n = 2 5})$ and surgeons over the age of $35(\mathbf{n = 2 8})$. The surgeon age could not be used as a covariate in regression analysis due to sparsity of the data.

Disposable sterile one-way surgical paper masks (Surgical Face Mask SLM/B, Sterilife, Yozgat, Turkey) were used and the mask position did not vary during the procedures (never below the nose). The same pulse oximeter with a reusable clip type finger probe (Cardiocap/5, DatexOhmeda, Helsinki, Finland) was used to measure the blood $\mathrm{O}_{2}$ saturation during the study. Participants were encouraged to speak and behave in their usual manner throughout the operation. To eliminate the effect of dehydration over a several hour case on both pulse rate and $\mathrm{O}_{2}$ saturation, the surgeons were allowed after every hour to drink water through a straw. For all measurements, finger probe was applied to the second finger of the right hand. The study was performed for over a 3-month period extending from March to May, while the operating room ambient temperature varied from 18 to $20^{\circ} \mathrm{C}$, and the relative humidity from 35 to $40 \%$.

Just before the operation, oxygen saturation and pulse rate values were recorded. At the end of the operation, pulse oximeter was applied again and the values were recorded. As the sham group, same surgeons were individually reassessed in the following days before and after exactly the same periods (between preoperational and post operational measurements) while they were standing in the operating room with their sterile gowns as an observer, not performing surgery and not wearing masks to obtain the pre control and post control values.

Paired and unpaired Student's t test were employed when comparing two groups such as pre and post operational values. The differences between the groups -more than two- were statistically evaluated using Kruskal-Wallis analysis of variance and than post hoc Dunn's test. Data are expressed as mean \pm standard error of mean (S.E.M.). Conditions were considered to be statistically significant when $\mathrm{p}<0.05$.

\section{Results}

When the values for oxygen saturation of hemoglobin were compared, there were statistically significant differences only between preoperational and post operational values (Fig. 1). As the duration of the operation increases, oxygen saturation of hemoglobin decreases significantly. Neither preoperational values, nor the post operational values in themselves were different among the groups. In the group of surgeons who did not wear masks during primary care operations with duration of less than 30 minutes, preoperational saturation values were $97.6 \pm 0.2$ while post operational values decreased to $96.3 \pm 0.3$ ( $\mathrm{p}=0.0006)$.

When preoperational and post operational pulse rates were compared, it was observed that pulse rate increased after the operations, and there was a statistically significant 


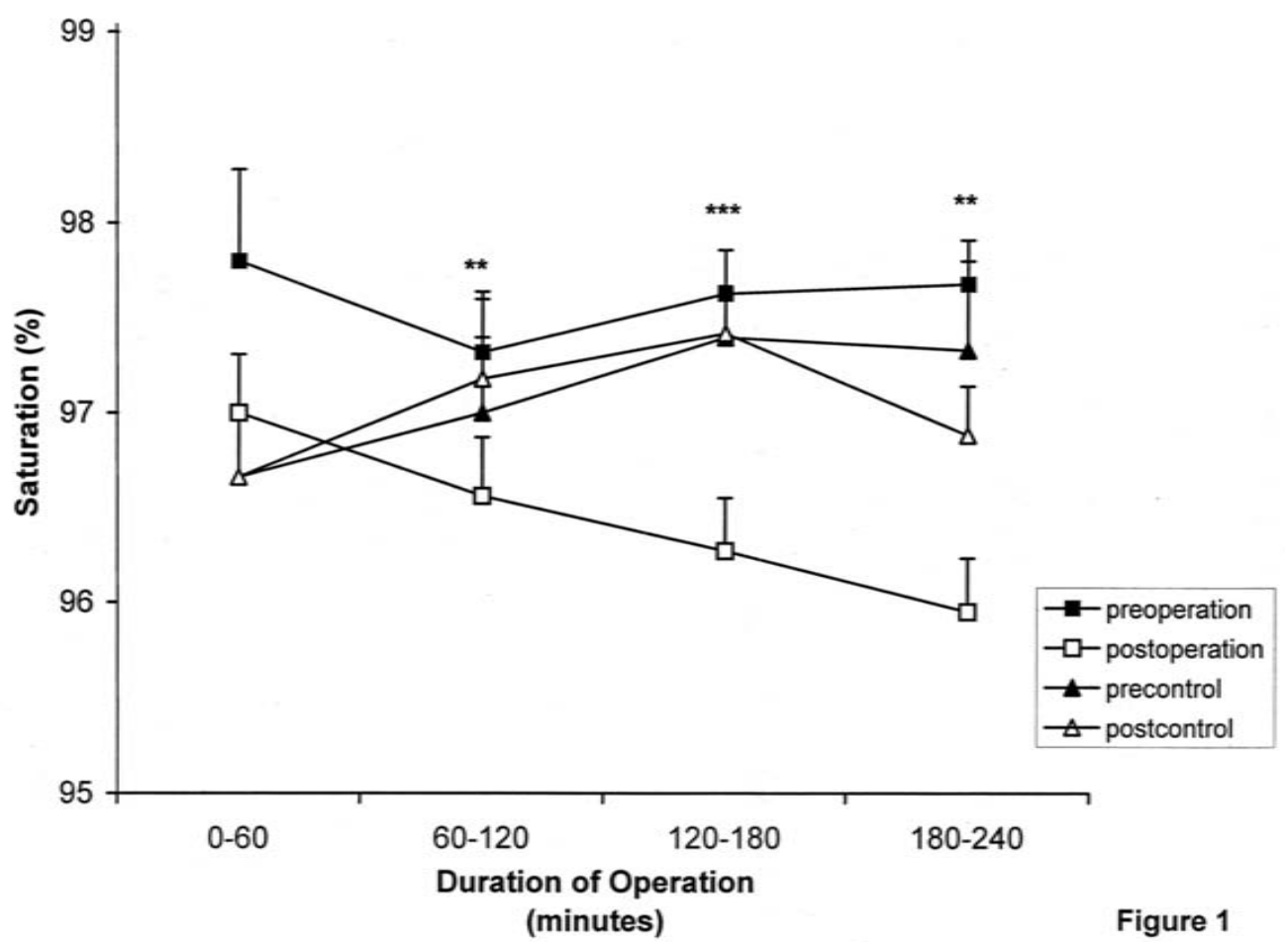

Figure 1. The changes in the oxygen saturation of hemoglobin by the duration of surgical operations. Data are expressed as mean \pm S.E.M.of $n$ surgical operations. There were statistically significant differences only between preoperational and post operational values. ${ }^{* *} p<0.01, * * * p<0.0001$

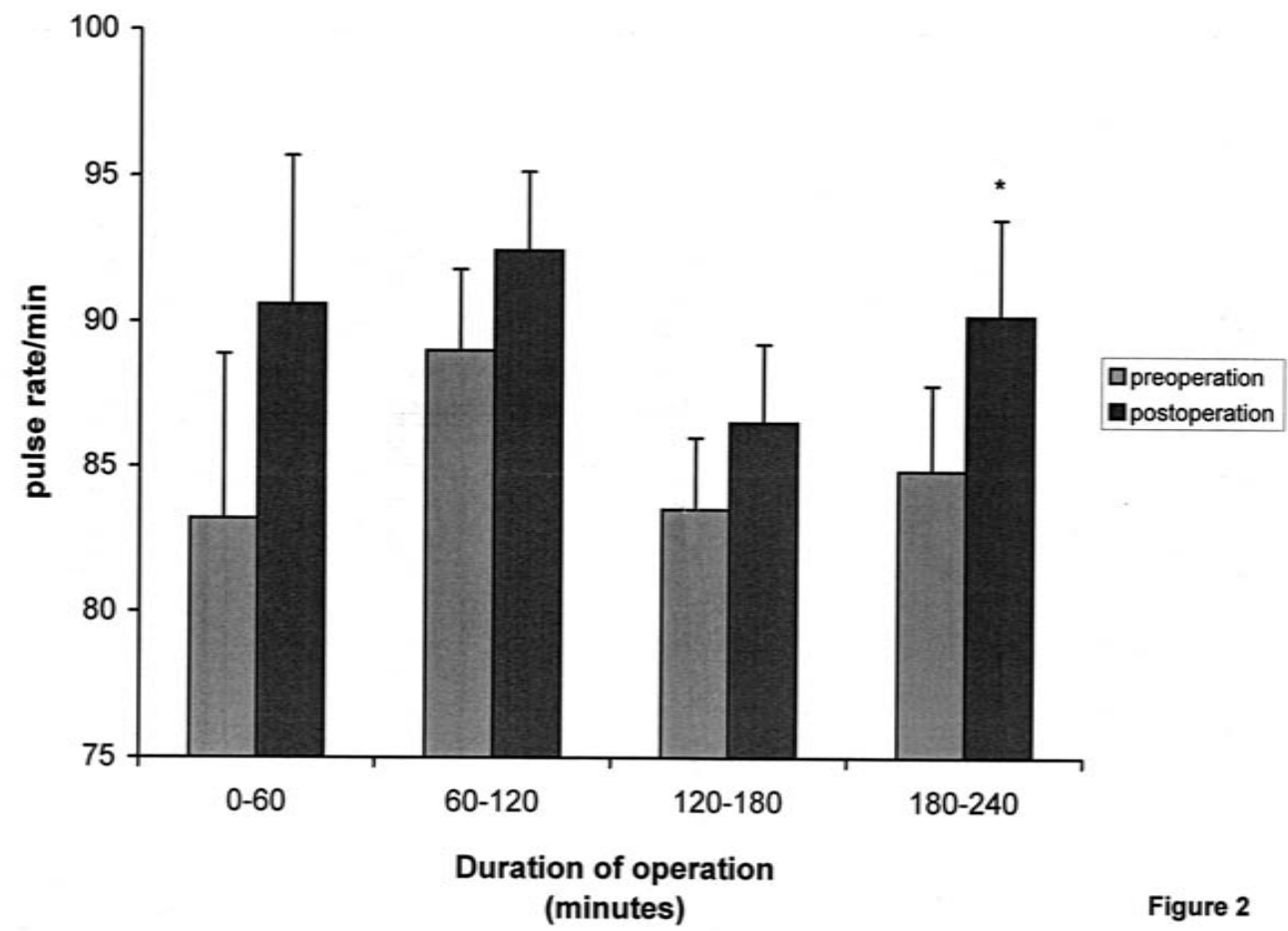

Figure 2: The changes in pulse rates by the duration of surgical operations. Data are expressed as mean \pm S.E.M. of $n$ surgical ope-rations. There was a statistica-lly significant difference only in the group in which operation duration was 180-240 minutes. $* p<0.05$. 

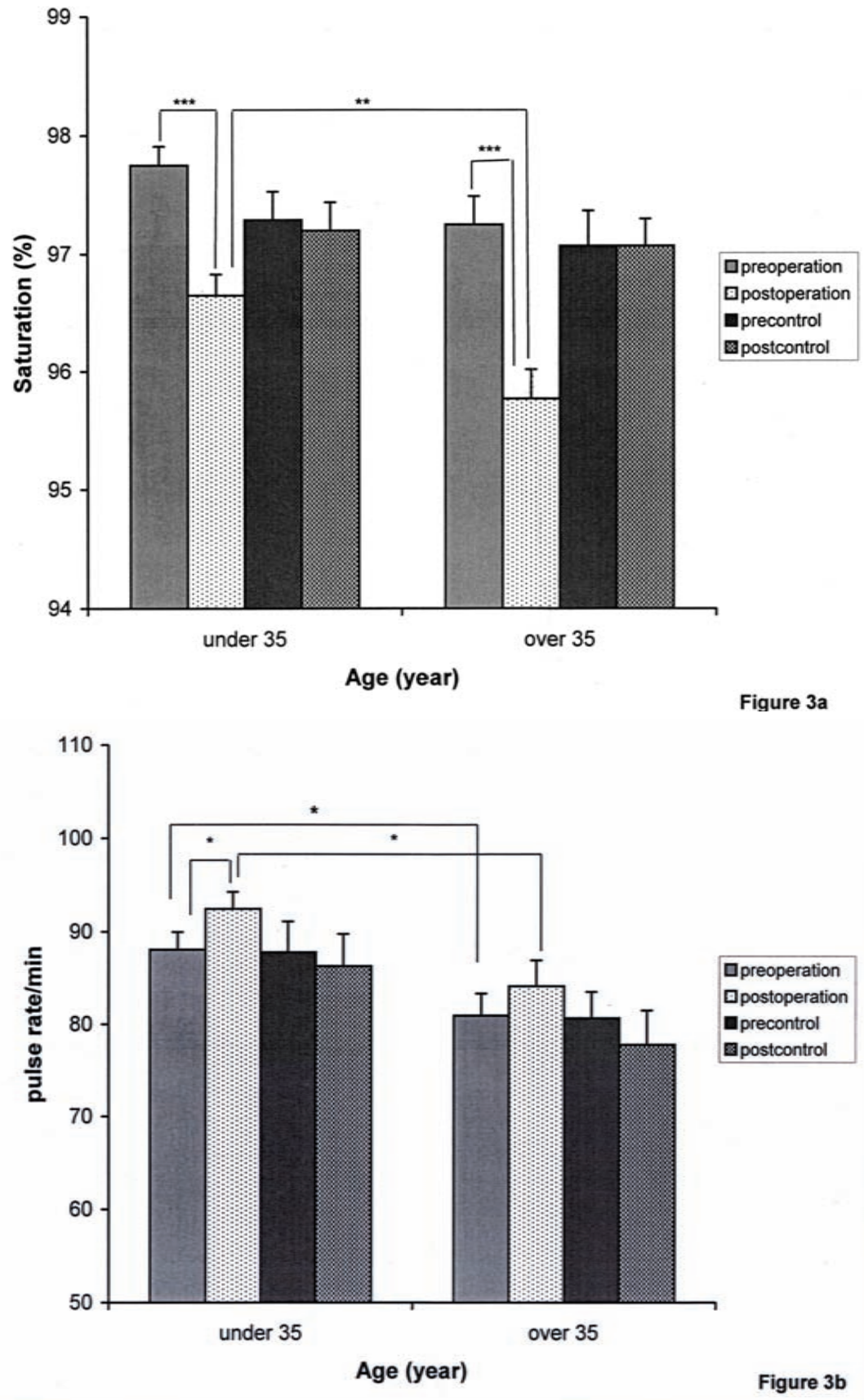

Figure 3. a: Effect of age on oxygen saturation of hemoglobin. $* * p<0.01, * * * p<0.0001$.

$b$ : Effect of age on pulse rates. $* p<0.05$.

difference only in the group in which operation duration was 180-240 minutes ( $\mathrm{p}=0.02$ ) (Fig. 2). Neither preoperational values, nor post operational values in themselves were different in the groups.

There was not any statistically significant difference between pre control and post control values of pulse rates and oxygen saturations $\left(\mathrm{SpO}_{2}\right)$ of the same surgeons, without facial masks while not performing surgery (Fig 1).
Oxygen saturation of hemoglobin decreased significantly after the operations in both age groups $(p<0.0001)$. The post operational decrease was more prominent in surgeons over 35 when compared to the surgeons under 35 $(\mathrm{p}=0.0073)$ (Fig. $3 \mathrm{a})$.

It was observed that pulse rate decreases by age. Both preoperational and post operational pulse rates were significantly different between the two age groups $(\mathrm{p}=0.0287$ 
and $\mathrm{p}=0.0124$ respectively) (Fig $3 \mathrm{~b}$ ). Under the age of 35 , pulse rate increases significantly after the operations $(\mathrm{p}=0.0207)$.

\section{Discussion}

Although decrease in both mental - physical performance and accuracy may sometimes be overcome by the motivation of the surgeon, increased fatigue is common in lengthy operations. The increased endogenous heat production of the surgeon, as well as many aspects of the operating room situation -even the close environment beneath the surgical mask- may also negatively affect the working condition of the surgeon. Surgical masks may impose some measurable airway resistance, but it seems doubtful if this significantly increases the process of breathing. Although it might have appeared to be likely that hypoxemia results from the increased $\mathrm{CO}_{2}$ content of the inspired air due to the exhaled $\mathrm{CO}_{2}$ getting trapped beneath the surgical face mask; there has been no controlled study concerning with the effect of surgical masks on the level of blood oxygenation. In this study we have measured the oxygen saturation of arterial pulsations $\left(\mathrm{SpO}_{2}\right)$ by a pulse oximeter and found a statistically significant decrease in the blood $\mathrm{O}_{2}$ saturation level of the surgeons post operationally, which is not due to prolonged standing or stress.

Pulse oximetry, nowadays considered as a standard of clinical care, is a non-invasive method used to measure arterial oxygen saturation with a clinically acceptable accuracy. Since pulse oximeters cannot be calibrated by the user, their performances had been evaluated under both normal (good perfusion, saturation within a normal range and no interfering substances or extraneous factors) and adverse conditions. Despite some performance limitations in the settings of carboxyhemoglobinemia, motion artifact, presence of intravascular dyes, change in systemic vascular resistance, hypotension, nail polish, vasoconstriction, and anemia ${ }^{2,7}$, it has been shown that age, gender, weight, body temperature, hemoglobin concentration and pulse pressure have little effect on the accuracy of pulse oximeters in detecting hypoxemia ${ }^{8}$. The majority of pulse oximeters have an absolute mean error of less than 1.0\% when compared to in vitro saturation measurements ${ }^{3,9}$. Pulse oximeters are limited by their software so as not to give a saturation reading greater than $100 \%$, and this limits the potential for positive errors and makes bias and precision calculations difficult to interpret in this high range. As the sigmoid shape of the blood oxygen dissociation curve flattens out at this high saturation levels $(>90 \%)$ and since even a very small decrease in saturation at this level reflects a large decrease in $\mathrm{PaO}_{2}$; our findings may have a clinical value for the health worker-surgeon: The surgeon's post operational blood $\mathrm{O}^{2}$ saturation level is decreased more than $1 \%$ although the variability of the saturation sensors is less than $1 \%$. It is thought that after a very short time the barrier function of the surgical face mask is gone ${ }^{6}$. Thus it is hard to believe that these masks serve as a reducer of oxygen uptake, but they may be acting as a psychological restriction over spontaneous breathing of the active surgeon.

Considering our findings, this is the first clinical investigation reporting a decrease in blood $\mathrm{O}_{2}$ saturation and an increase in pulse rates of the surgeons after the operations due to surgical mask usage. This change in $\mathrm{SpO}_{2}$ may be either due to the facial mask or the operational stress, since similar changes were observed in the group performing surgery without a mask. However, it cannot be decided whether stress plays any role on the late changes, namely pulse rate increase and $\mathrm{SpO}_{2}$ level decrease; since surgeons are not allowed to perform major surgery without a facial mask in most institutions. In order to better elucidate the effects of stress, a randomized control study should have been conducted in a more controlled environment with different sorts of workers from different gender who are or are not used to wearing face masks on (such as anesthesiologists, nurses) also working the same durations. Thus, it is important not to generalize the results of this preliminary study, and further studies involving measurement of gas tensions over time, both from blood and from samples obtained under the mask (in order to show a presumed build-up of $\mathrm{CO}_{2}$ under the mask) have to be carried out to elucidate this issue.

\section{References}

1. Beck, W.C.: The air permeability of surgical masks. Guthrie Clin Bull 1964; 34: 26.

2. Jensen, L.A., Onyskiw, J.E., Prasad, N.G.: Meta-analysis of arterial oxygen saturation monitoring by pulse oximetry in adults. Heart Lung 1998; 27: 387-408.

3. Kagle, D.M., Alexander, C.M., Berko, R.S., et al.: Evaluation of the Ohmeda 3700 pulse oximeter: steady state and transient response characteristics. Anaesthesiology 1987; 66: 376-380.

4. Mayers, J.R.: Patient Monitors. In: Morgan EG, Mikhail MS, Murray MJ, Larson CP (eds). Clinical Anesthesiology. $3^{\text {rd }}$ ed, Lange; Mc Graw Hill, 2002; pp.86-126

5. Mikulicz, J.: Das Operieren in sterilisierten Zwirnhandschuhen und mit Mundbinde. Centralblatt für Chirurgie 1897; 26: 714-717. (cited in ref. No. 6).

6. Romney, M.G.: Surgical face masks in the operating theatre: re-examining the evidence. Journal of Hospital Infection 2001; 47: 251-256.

7. Sinex, J.E.: Pulse oximetry: principles and limitations. Am J Emerg Med 1999; 17: 59-67.

8. Villanueva, R., Bell, C., Kain, Z.N., et al.: Effect of peri- 
pheral perfusion on accuracy of pulse oximetry in children. $\mathrm{J}$ Clin Anesth 1999; 11: 317-322.

9. Webb, R.K., Ralston, A.C., Runciman, W.B.: Potential errors in pulse oximetry. Anaesthesia 1991; 46: 207212.
Beder, A.; Büyükkoçak, Ü.; Sabuncuoğlu, H.; Keskil, Z.A.; Keskil, S.: Preliminary report on surgical mask induced deoxygenation during major surgery. Neurocirugía 2008; 19: $121-126$.

Corresponding author: Prof. Dr. Semih Keskil, M.D., Ph.D. Fethiye Sokak No: 4/6. Gazi Osman Pasa. 06700 Ankara Turkey. 